\title{
Evaluation of Woven Agrotextiles in the Development of Hemp (Cannabis sativa L.) in Greenhouse
}

\author{
Antigolena FOLINA ${ }^{1}$, Ioannis ROUSSIS ${ }^{1}$, Varvara KOUNELI ${ }^{1}$, Ioanna KAKABOUKI ${ }^{1}$, Stella \\ KARIDOGIANNI ${ }^{1}$, Dimitrios BILALIS ${ }^{1 *}$, Nikolaos KADOGLOU ${ }^{2}$
}

${ }^{1}$ Agricultural University of Athens, Department of Crop Science, Laboratory of Agronomy, 75 Iera Odos St., 11855 Athens, Greece

${ }^{2}$ THRACE Nonwovens \& Geosynthetics S.A., 20 Marinou Antypa St., 17455 Alimos, Athens, Greece

*corresponding author, email: bilalisdimitrios@gmail.com

BulletinUASVM Horticulture 77(1) / 2020

Print ISSN 1843-5254, Electronic ISSN 1843-5394

DOI:10.15835/buasvmcn-hort: 2019.0023

\begin{abstract}
The effect of the reflection by a white agrotextile, in hemp cultivation, was evaluated on a greenhouse experiment during 2019. The experiments were laid out in a completely randomized design with two treatments (soil cover and control). The results indicated that the average temperature in the covered area section was $28.5^{\circ} \mathrm{C}$ while in the uncovered area was $25.12^{\circ} \mathrm{C}$, during the experiment. Concerning height, higher plants up to $20 \mathrm{~cm}$, were recorded on the covered area than the uncovered one. The highest specific leaf area (SLA) $\left(58.39 \mathrm{~cm}^{2} \mathrm{~g}^{-1}\right)$ was found on the covered area at 60 days after transplanting (DAT) compared to the uncovered area where a value of $50.4 \mathrm{~cm}^{2} \mathrm{~g}^{-1}$ was recorded. The absolute growth rate was higher during 20-60 DAT comparatively to control. The highest rate was observed about 50-60 DAT where it reached the value of $3.34 \mathrm{~g} \mathrm{day}^{-1}$. Concerning root system, arbuscular mycorrhizal fungi (AMF) was only affected by the cover material. The number of inflorescences was not found to be affected by the cover material but the bud length and the cannabidiol (CBD) content were affected by the soil cover. The cannabinoids (CBD) content was $28.8 \%$ higher on covered area.
\end{abstract}

Keywords: Absolute Growth Rate, CBD, Light Below Canopy, plastic mulch, Specific Leaf Area

\section{Introduction}

Agro-textile (agrotextile) or geo-textile (geotextile) is used in agriculture for decades, in a traditional way (Restrepo Osorio et al., 2019). Mainly, the term used in agriculture is mulching which means the application of natural or synthetic materials on surface area to create the desirable environment for different crops (Manna et al., 2018). They are applied at various times of the year depending on the purpose. Also, there are many materials used as mulches, such as organic residues, compost or plastic mulch. Nowadays, the use of geotextiles is expanding worldwide (Gangopadhyay and Hira, 2010). Corresponding to the state of technology, new age agrotextiles are made with new, developed materials (or natural) and they have better standards (e.g. durability, performance etc.) (Swapan et al., 2016; Scarlat et al., 2017). The use of agrotextiles is aimed to optimize the environmental condition such as moisture retention, water conservation, weed or sward suppression, soil warmth retention, and light reflection (Carpus et al., 2018; Marasović and Dragana, 2019; Restrepo Osorio et al., 2019). 
Table 1. Soil and compost analysis

\begin{tabular}{ccc}
\hline & Soil & Compost \\
& Clay Loam $(29.3 \%$ Clay, 33.8\% Silt and 36.9\% Sand) & \\
\hline $\mathrm{pH}$ & 7.17 & 7.6 \\
\hline Olsen- P $\left(\mathrm{mg} \mathrm{kg}^{-1}\right.$ soil) & 13.2 & 410 \\
\hline Evailable potassium $(\mathrm{K})\left(\mathrm{mg} \mathrm{kg}^{-1}\right.$ soil) & 201 & 620 \\
\hline Organic $\mathrm{MS} / \mathrm{cm})$ & 47.5 & 9.65 \\
\hline
\end{tabular}

Rathinasabapathi et al. (2005) were noticed that mulching inhibited the weed germination except of the weed suppression. In some applications, the combination of natural light and agro- and geotextiles could be desirable, for example in horticultural applications for promoting crop growth or crop production such as resin. Manna et al. (2018) observed the highest average curd weight of broccoli (355.25 g) on covered area. Additionally, Albert et al. (2010) noticed that mulching with synthetic (polyethylene film) or organic materials has been widely used for the production of widely ordered commercial crops and vegetables, such as tomatoes and lettuce.

On the other hand, the use of agrotextiles focus on reducing the sun radiation as well as thermal protection of plants as shade cloth, furthermore for preventing insect and other pests on crops, preventing soil drainage and sediment creation (Marasović and Dragana, 2019). In addition, Marasović and Dragana (2019) highlight as main role of the agrotextiles in protection against insects. In agriculture as far as soil coverage offers many benefits, recycled materials are used usually as agrotextiles (Anade, 2013; Bhatt et al., 2019). In agriculture, one of the parameters of agrotextiles that should be clarified is the porosity. Most of the agrotextiles are used in field conditions, so the porosity is a characteristic that is examined to get through rainwater or irrigation (Dierickx, 1999). Restero Osorio et al. (2019) denoted that agrotextiles can offer UV radiation stability after the appropriate treatment.

Geotextiles have considerable potential for solar exploitation, but few studies have been completed on their effects on aboveground biomass production. The number of production units for medical cannabis increase every day in Greece (Folina et al., 2019) so the need to study and understand the behavior of this crop increases alongside. A greater number of harvests per year could be achieved with more use of artificial light, but then the cost advantage of greenhouse growing begins to evaporate. So, cannabis producers of greenhouse hemp installed artificial light to increase the biological cycles or harvest of the cannabis plant per year. Of course, the artificial light should be combined additionally with mechanical factors (such as $\mathrm{CO}_{2}$ ). In these economical scales could be included the use of agrotextiles. Greece has 220 days of light per year sunshine with the intensity of radiation that plants absorb. Taking advantage of the key features of Greece's climate, we used a white geotextile to exploit the intensity of radiation through the reflection created by the geotextile. The aim of the study was to evaluate whether the reflection of radiation created by the geotextile affects the growth and the cannabinoids (CBD) content of hemp.

\section{Materials and methods}

\section{Experimental details and treatments}

A greenhouse experiment was conducted at the Agricultural University experimental area of Laboratory of Agronomy, located in Athens (Southern Greece, latitude: $37^{\circ} 58^{\prime} \mathrm{N}$, longitude: $23^{\circ} 32^{\prime} \mathrm{E}$, altitude $30 \mathrm{~m}$ above sea level) from February to May 2019. Hemp cultivation was carried out in pots filled with soil and compost. Cultivation began with the formation of seedlings - in a float system - and then the seedlings were transplanted into pots (soil : compost, 1:1) by hand to a depth of $2-3 \mathrm{~cm}$, one plant per pot. The pot density was four pots per $1 \mathrm{~m}^{2}$. The experiment was set up on an area of $800 \mathrm{~m}^{2}$, according to the completely randomized design with two replicates. The treatments were soil cover area (CA) with a geotextile and uncovered area (UA) as control. The 
agrotextile used as cover material applied on soil surface was a woven fabric made of polypropylene for long term exposure to sunlight and flame resistance. The pots on covered area were placed on the white agrotextile. The greenhouse space was divided into 4 parts (plots), two of them were covered with the geotextiles and the other two remained uncovered.

\section{Measurements}

The measurements were height, fresh and dry weight, photosynthetically active radiation (PAR) to calculate Light Below Canopy (L.B.C., equation 1), leaf temperature, Specific Leaf Area (equation 2 ), Absolute Growth Rate ( $\mathrm{g} \mathrm{m}^{-2}$ day $^{-1}$ ) (equation 3 ), yield parameters (number of inflorescences, average length, inflorescence weight) and CBD content (\%). Plant-based illumination expressed as a percentage of PAR was greater in the soil cover plots. The higher values are due to the reflection of the material and the differences are increasing as the crop growth and leaf area increase.

$$
\begin{aligned}
& \text { L.B.C. }(\%)=\frac{\text { PARbelow }}{\text { PARabove }} \times 100 \\
& S L A=\frac{\text { one-sided area of a fresh leaf }}{\text { leaf dry mass }}\left(\mathrm{cm}^{2} \mathrm{~g}^{-1}\right) \\
& A G R=\frac{W 2-W 1}{P(t 2-t 1)}\left(\mathrm{g} \mathrm{m}^{-2} \text { day }^{-1}\right)\left(\mathrm{g} \mathrm{m}^{-2} \mathrm{day}^{-1}\right)
\end{aligned}
$$

where: $\mathrm{W} 1=$ plant dry weight $/ \mathrm{m}^{2}$ at $\mathrm{t} 1$, and $\mathrm{W} 2=$ plant dry weight $/ \mathrm{m}^{2}$ at $\mathrm{t} 2$.

Two plant samples were randomly selected from each plot at 15, 20, 25, 30, 35, 40, 45, 5060 70 and 80 Days After Transplanted (DAT). The plants collected were divided into stems, leaves and flowers, weighted and oven-dried for $48 \mathrm{~h}$ at $65^{\circ} \mathrm{C}$. The photosynthetically active radiation was measured with the SS1 SunScan Canopy Analysis System. The PAR was measured above and below the foliage to evaluate the effectiveness of the material's reflective properties. For leaf was used temperature an infrared thermometer pronto plus. The thermometer was kept on the center of leaf for less than one minute. For each plant, at least two leaves were recorded. The measurements of PAR and temperatures were noticed at 12:00 p.m, every time.

The root system parameters determined were: root length density (RLD), root mass density (RMD), root surface density (RSD) and arbscular mycorrhiza (AMF). Root samples were collected from the $0-35 \mathrm{~cm}$ layer by using a cylindrical auger (25 cm length, $10 \mathrm{~cm}$ diameter). Root measurements were made at flowering stage using five randomly selected plants (pots) per plot. Firstly, roots were separated from the soil by soaking the samples overnight in $30 \mathrm{ml}$ of a $0.5 \%$ solution of sodium hexametaphosphate. Afterwards, the samples were stirred for $5 \mathrm{~min}$ and washed over a $5 \mathrm{~mm}$ mesh-sieve. The roots thus held on the sieves were decanted into a $0.1 \%$ trypan blue FAA staining solution (mixture of $10 \%$ formalin, $50 \%$ ethanol and 5\% acetic acid solutions). For the determination of root length density (RLD) and root surface (RS), the stained root samples were placed on a high resolution scanner (Hewlett Packard 4c, Palo Alto, CA, USA) and images were captured using Delta-T software (Delta-T Scan version 2.04; Delta-T Devices Ltd, Burwell, Cambridge, UK). The root dry mass density (RMD) was determined after drying for 48 $\mathrm{h}$ at $70^{\circ} \mathrm{C}$. The second root samples were cleaned and stained with trypan blue in lactophenol, according to the method of Phillips and Hayman (1970). The percentage of root length colonized by AM fungi was determined microscopically with the gridline intersection method at a magnification of 30-40× (Giovannetti and Mosse, 1980).

For the determination of CBD content, ten fresh inflorescences from each plot were subjected to this measurement using the GemmaCert device machine (GemmaCert Ltd., Israel).

\section{Data analysis}

The experimental data were checked for normality and subjected to statistical analysis according to completely randomized design (CRD). The statistical analysis was performed with the SigmaPlot 12 software (Systat Software Inc., San Jose, CA). Differences between means were separated using Least Significant Difference (LSD) test. All comparisons were made at the $5 \%$ level of significance.

\section{Results and discussion}

Light (\%) at the base of the crop

During the first few days, due to the slow growth of plants, there are no significant differences. After the 20 DAT, the difference between the two treatments was $7 \%$ more radiation for the $\mathrm{CA}$. At the beginning of flowering (50-60 DAT) the difference reached $12 \%$ in favour CA (Fig. 1). Therefore, an average of about $10 \%$ was observed over the vegetative period. In particular, 


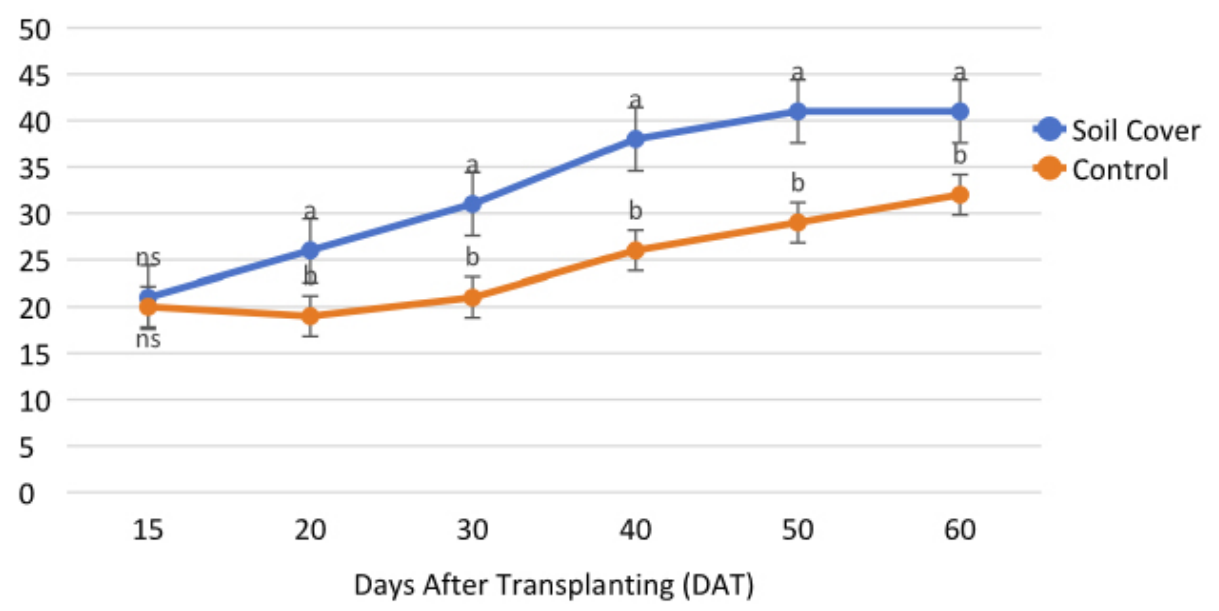

Figure 1. Light below canopy (\%) at the base of hemp in pot cultivation expressed as a percentage of growth stimulation during the vegetative period for the CA (soil cover) and UN (control)

Different letters denote significant differences between the treatments according to LSD test $(\mathrm{P}<0.05)$

this difference can offer a final reduction in production costs up to $5 \%$, since the light energy represents $50 \%$ of the total cost (Deloitte, 2016). Contrariwise, Struik et al. (2000) mentioned that the radiation use efficiency changed during plant development, being lower during flowering than vegetative stage.

\section{Leaf temperature}

Due to the higher photosynthetic active radiation (PAR), leaf temperature was higher at CA as expected (Fig. 2). During the experiment, the mean temperature at $\mathrm{CA}$ was $28.5^{\circ} \mathrm{C}$ while at the UA was $25.12^{\circ} \mathrm{C}$.

According to the climate of Greece, higher temperature is particularly desirable during October to April when the heating needs could be reduced by using the agrotextiles. However, when the temperatures rise above $35^{\circ} \mathrm{C}$, the soil coverage works negatively. Werf et al. (1995) observed that rates of leaf appearance and stem elongation increased linearly with temperature between $10^{\circ} \mathrm{C}$ and $28^{\circ} \mathrm{C}$. Kobza et al. (1987) noticed that leaf temperature on wheat was $15-25^{\circ} \mathrm{C}$.

\section{Plant height}

Plants on CA were higher than those on the UA. Although, after the $60^{\text {th }}$ DAT, plants stopped growing because they reached the final height and due to the effect of high temperature in the greenhouse, stress conditions began to occur and accelerated the flowering of the plants (Fig. 3). Chailakhyan and Khryanin (1978) in a pot experiment noticed mean plant height at $30 \mathrm{~cm}$ because of the limited development space.
In field conditions, without any fertilization cannabis height was $78.2 \mathrm{~cm}$ (Vera et al. 2004) and $250 \mathrm{~cm}$ (Jankauskienè et al., 2010). It is noted that the plants grown in the greenhouse with the white agrotextile, which offers greater radiation and temperature, were equal and taller than those grown in the open field.

\section{Specific Leaf Area $\left(\mathrm{cm}^{2} \mathrm{~g}^{-1}\right)$}

The effect of photosynthetic radiation also affected the leaf surface beyond the mid-span intervals. Specifically, the highest specific leaf area (SLA) $\left(58.39 \mathrm{~cm}^{2} \mathrm{~g}^{-1}\right)$ was found on the covered area at 60 DAT compared to the uncovered area where a value of $50.4 \mathrm{~cm}^{2} \mathrm{~g}^{-1}$ was recorded. At 20 DAT, the SLA was $36.1 \mathrm{~cm}^{2} \mathrm{~g}^{-1}$ on the CA and 32.8 $\mathrm{cm}^{2} \mathrm{~g}^{-1}$ on control, while, at $40 \mathrm{DAT}$, the values were 47.2 and $41.7 \mathrm{~cm}^{2} \mathrm{~g}^{-1}$ on the covered area and control, respectively (Fig. 4). Differences in SLA cannot be explained in terms of maximizing photosynthetic function alone (Dijkstra, 1989).

Plant dry weight without inflorescence $(g)$

Dry weight follows a sigmoidal growth path. Coverage excellence starts at 45 DAT and the dry weight accumulation at 70 DAT stabilizes (Fig. 5).

The final percentage of difference is $15.12 \%$. Greater leaf growth and higher photosynthetic active radiation led plants to higher photosynthesis rates, resulting in greater accumulation of photosynthetic products and higher dry weight (Bhattacharyya et al., 2012). According to the literature, similar results were obtained for plant dry weight namely $14.1 \mathrm{~g}$ (Struik et al., 2000) and $10.3 \mathrm{~g}$ (Werf et al., 1994). 


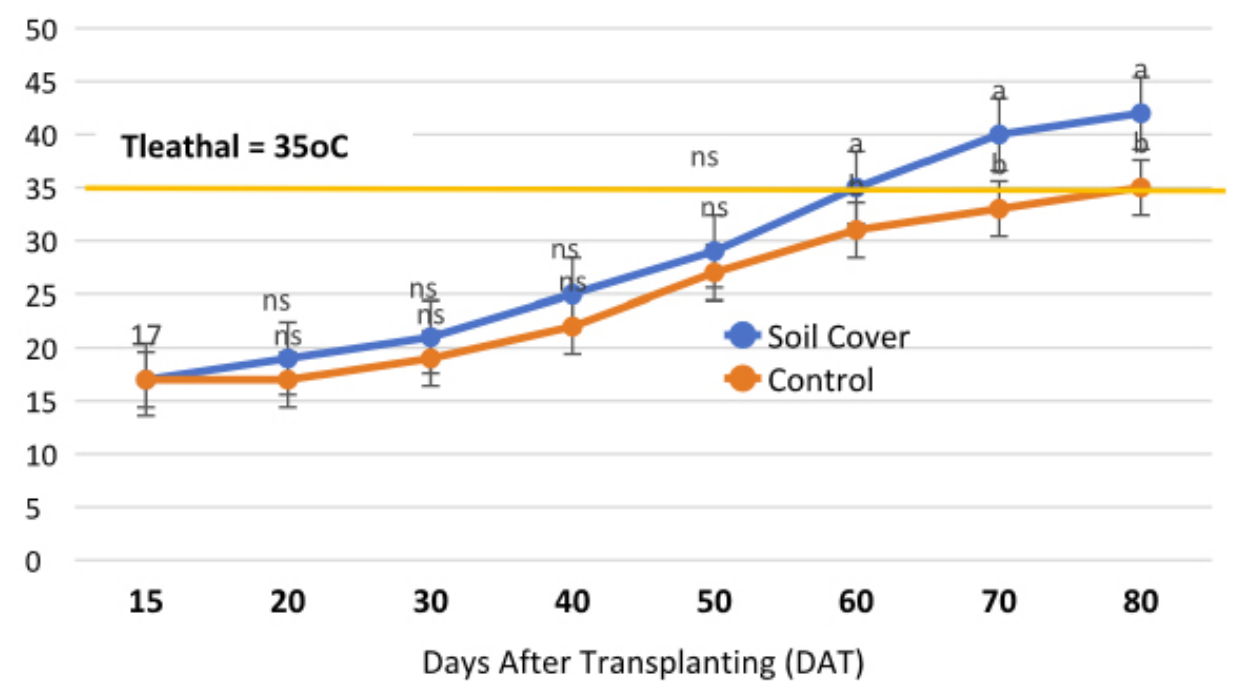

Figure 2. Leaf temperature $\left({ }^{\circ} \mathrm{C}\right.$ ) of hemp plant in pot cultivation on the CA (soil cover) and UN (control) Vertical bars indicate the standard errors of the means. Different letters denote significant differences between the treatments according to LSD test $(\mathrm{P}<0.05)$.

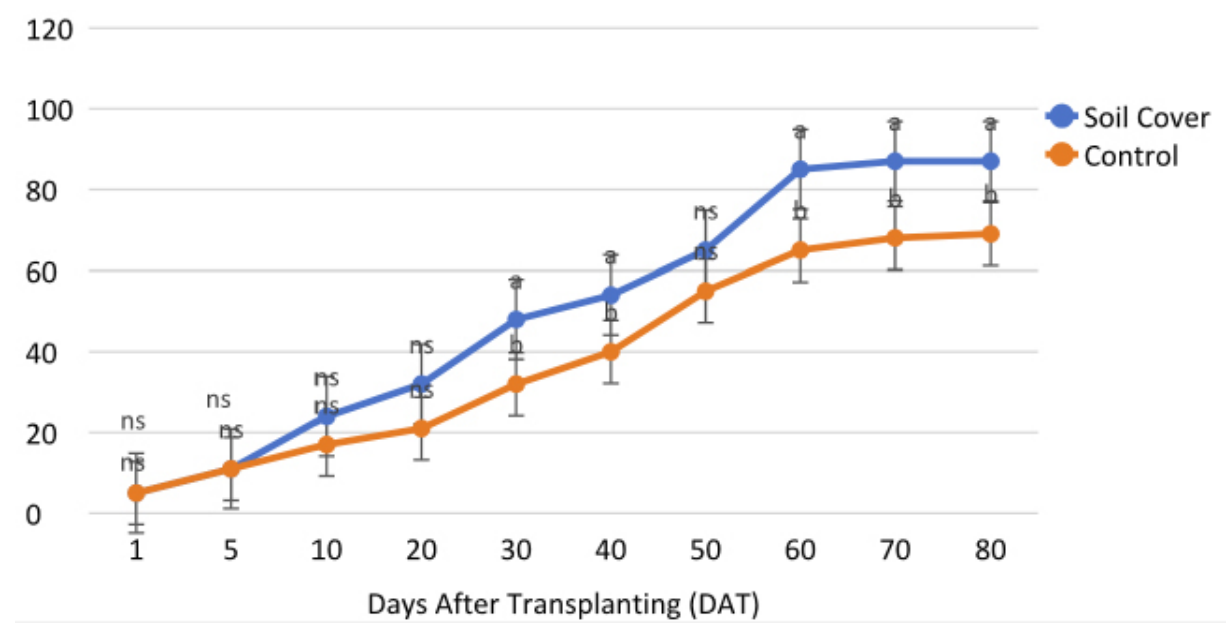

Figure 3. Plant height (cm) development of hemp in pot cultivation on CA (soil cover) and UN (control) Vertical bars indicate the standard errors of the means. Different letters denote significant differences between the treatments according to LSD test $(\mathrm{P}<0.05)$.

\section{Absolute Growth Rate (g day-1)}

According to Figure 6, from 20 to 60 DAT, the soil coverage gave higher growth rates than the uncovered areas. The highest rate was observed around 50-60 DAT where it reached the value of $3.34 \mathrm{~g} \mathrm{day}^{-1}$. However, in the CA after 60 DAT and with the advent of high foliage temperatures, the plants showed stress and reduced growth rate, even to lower values than in the UA. The negative value presented at the end is due to the fact that the plants lose leaves and consequently the dry weight decreases. This indicator confirms the principle that when the foliage temperature exceeds $35^{\circ} \mathrm{C}$ the cover material must be removed as the relative growth rate decreases. Similarly, Lydon et al. (1987) mentioned that one of the factors which influence hemp growth is UV-B insensitivity. The increase of radiation also increases the temperature inside the greenhouse and the absolute growth rate of the plant on the covered soil is higher. Similar results have been shown by Criddle (1996) confirming that plant growth rates vary with temperature. 


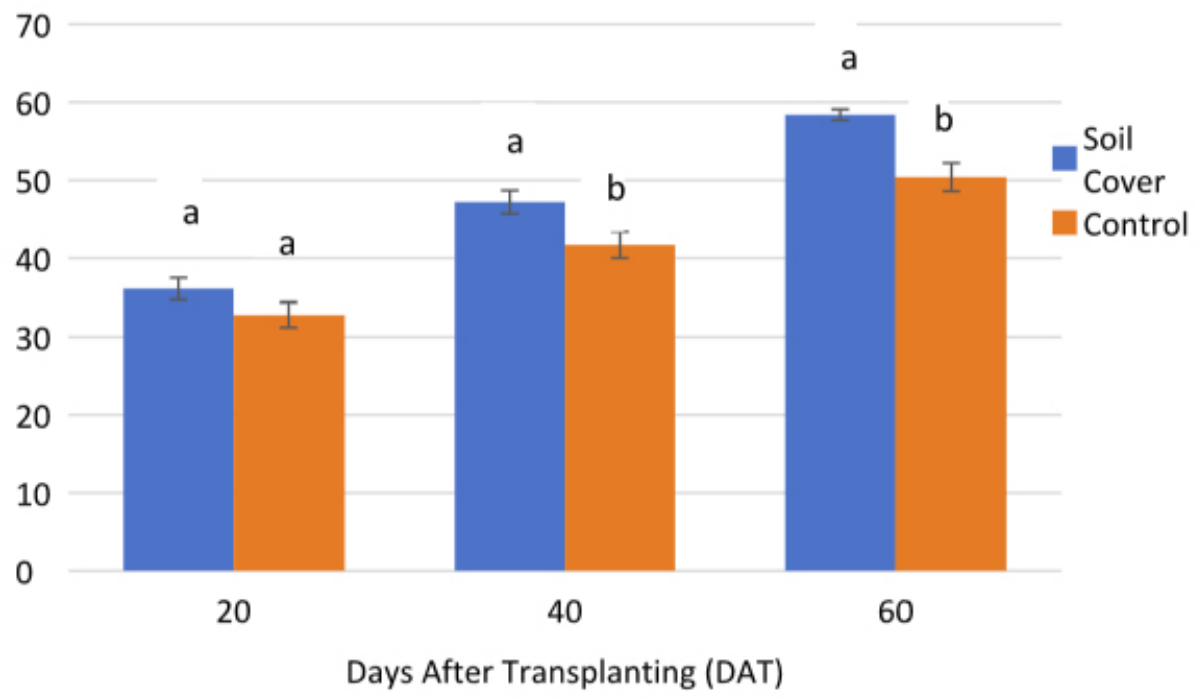

Figure 4. Specific Leaf Area $\left(\mathrm{cm}^{2} \mathrm{~g}^{-1}\right)$ hemp plant in pot cultivation on at 20, 40 and 60 DAT Vertical bars indicate the standard errors of the means. Different letters denote significant differences between the treatments according to LSD test $(\mathrm{P}<0.05)$.

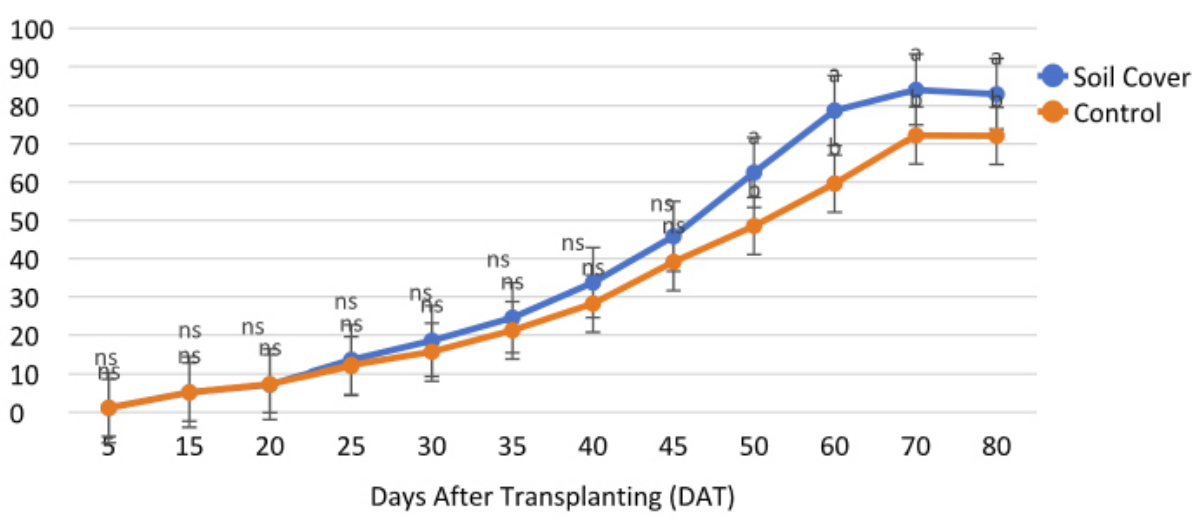

Figure 5. Dry weight (g) of hemp plant in pot cultivation on CA (soil cover) and UA (control) Vertical bars indicate the standard errors of the means. Different letters denote significant differences between the treatments according to LSD test $(\mathrm{P}<0.05)$.

\section{Hemp Root System}

The growth of the root system at 60 DAS was greater in pots on CA. The better temperature conditions of the plant and its need for increased photosynthesis have led the plant to develop a larger root system to meet its nutritional needs. Amaducci et al. (2008) mentioned that hemp root system may be affected by the soil depth.

A higher root mass density was observed on CA. The RMD at CA was $1.35 \mathrm{~g} / 100 \mathrm{~cm}^{3}$ of soil, compared to the UA $\left(1.11 \mathrm{~g} / 100 \mathrm{~cm}^{3}\right.$ of soil). The winter barley (H. vulgare cv. Niki) has $0.332 \mathrm{~g} / 100$ $\mathrm{cm}^{3}$ mass density (Sidiras et al., 2001).
The surface area of the root system was 9.56 $\mathrm{cm}^{2} / 100 \mathrm{~cm}^{3}$ on CA and $7.85 \mathrm{~cm}^{2} / 100 \mathrm{~cm}^{3}$ of soil on UA. For winter barley ( $H$. vulgare cv. Niki) the surface density was $0.221 \mathrm{~g} / 100 \mathrm{~cm}^{3}$ mass density (Sidiras et al., 2001).

Root Length Density (RLD) is the most frequently estimated parameter to determine root morphology (Vamerali et al., 2003; Bilalis et al., 2015). Finally, a further qualitative feature of root growth where the plants on CA predominated was the length density of the root system where the value was $21.11 \mathrm{~cm} / 100 \mathrm{~cm}^{3}$ of soil while on UA the value was $16.87 \mathrm{~cm} / 100 \mathrm{~cm}^{3}$ of soil. The 


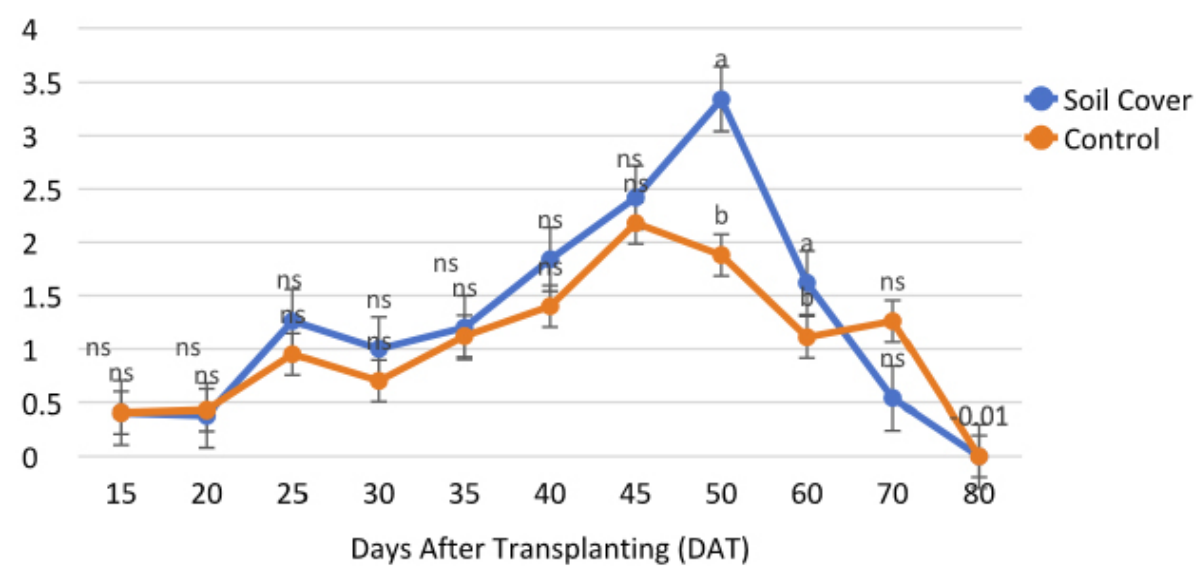

Figure 6. Absolute Growth Rate ( $\mathrm{g} \mathrm{day}^{-1}$ ) of hemp in pot cultivation on the CA (soil cover) and UA (control) Vertical bars indicate the standard errors of the means. Different letters denote significant differences between the treatments according to Least Significant Difference (LSD) test $(\mathrm{P}<0.05)$.

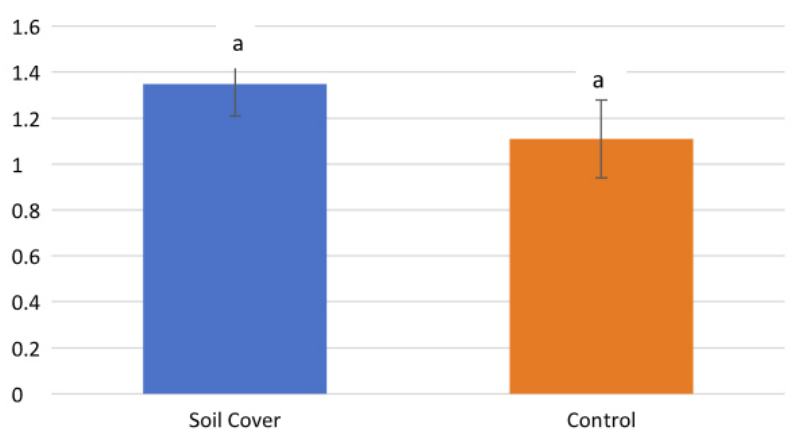

Figure 7. Root Mass Density (g/100 $\mathrm{cm}^{3}$ soil) of hemp in pot cultivation on CA (soil cover) and UA (control) Vertical bars indicate the standard errors of the means. Different letters denote significant differences between the treatments according to Least Significant Difference (LSD) test $(\mathrm{P}<0.05)$.

root length density was highest in the first $10 \mathrm{~cm}$ of soil, almost $5 \mathrm{~cm} / 100 \mathrm{~cm}^{3}$.

Mycorrhizal colonization is the mostimportant biological factor contributing to the absorption of nutrients as well as to the synthesis of biosynthetic substances that may contribute to the synthesis of terpene and CBD. Arbuscular mycorrhizal fungi (AMF) was positively affected by root growth and temperature (Ryan and Graham, 2002). The values observed on CA were 32\% regarding root length versus $19 \%$ on UA. As a conclusion about root system we can state that only AMF was affected by the soil coverage. The plastic behavior confirmed by Amaducci et al. (2008) who refer that none of

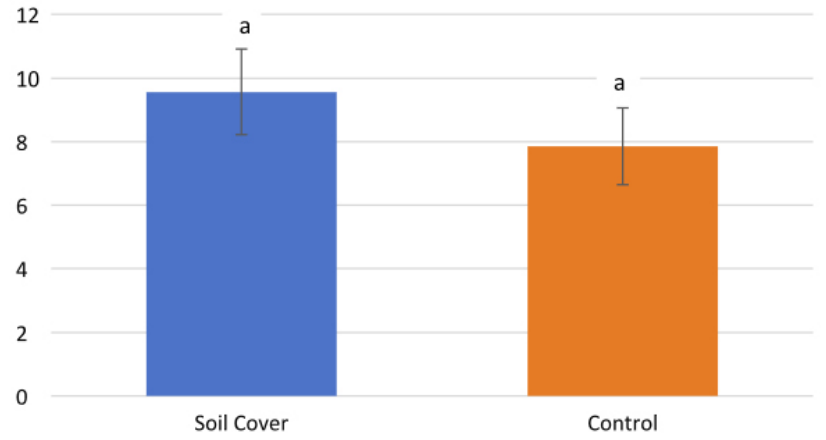

Figure 8. Root Surface Density $\left(\mathrm{cm}^{2} / 100 \mathrm{~cm}^{3}\right.$ soil) of hemp in pot cultivation on CA (soil cover) and UA (control)

Vertical bars indicate the standard errors of the means. Different letters denote significant differences between the treatments according to Fisher's Least Significant Difference (LSD) test $(\mathrm{P}<0.05)$.

the root parameters were significantly affected by plant population.

\section{Yield components}

The number of inflorescences was not found to be affected by the cover material. This character is mainly controlled by genetic factors rather than by cultivation manipulations. Therefore, no statistical effect on the number of inflorescences was observed. Thus, the plant blossomed properly giving only one inflorescence. The same was observed for the inflorescence length where no differences were noted between the agrotextile covered soil and the plants in the open cuts with the mean inflorescence length being about $19 \mathrm{~cm}$ (Tab. 2). 


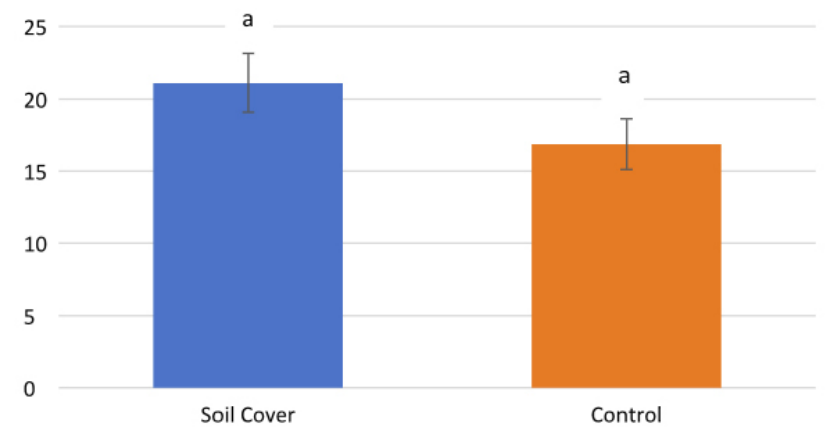

Figure 9. Root Length Density $\left(\mathrm{cm} / 100 \mathrm{~cm}^{3}\right.$ soil) of hemp in pot cultivation on CA (soil cover) and UA (control)

Vertical bars indicate the standard errors of the means. Different letters denote significant differences between the treatments according to Fisher's Least Significant Difference (LSD) test $(\mathrm{P}<0.05)$

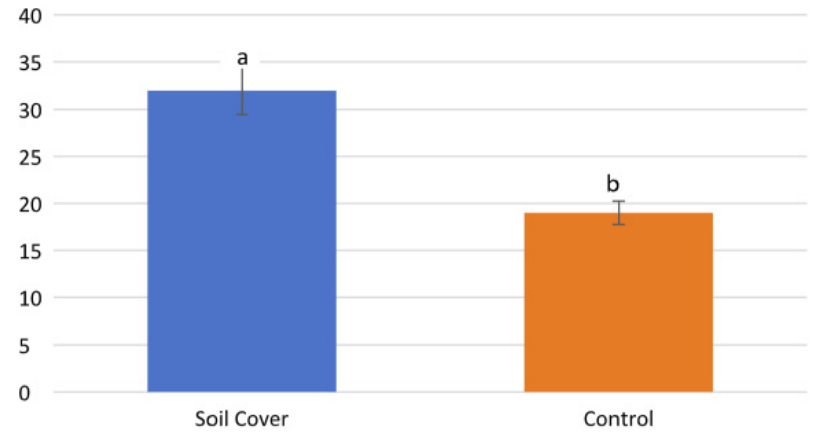

Figure 10. Arbuscular Mycorrhizal Fungi (\%) of hemp in pot cultivation on CA (soil cover) and UA Vertical bars indicate the standard errors of the means. Different letters denote significant differences between the treatment according to Fisher's Least Significant Difference (LSD) test $(\mathrm{P}<0.05)$.

Table 2. Influence of geotextiles on bud number, length and dry weight, compactness index and CBD for the two treatments (covered and uncovered area)

\begin{tabular}{cccccc}
\hline & Number of buds & Bud length (cm) & Bud dry weight (g) & $\begin{array}{c}\text { Compactness } \\
\text { index }\end{array}$ & CBD (\%) \\
\hline CA & $1.1 \mathrm{a}$ & $19.24 \mathrm{a}$ & $21.11 \mathrm{a}$ & $1.10 \mathrm{a}$ & $2.515 \mathrm{a}$ \\
\hline UA & $1.0 \mathrm{a}$ & $19.02 \mathrm{~b}$ & $16.87 \mathrm{a}$ & $0.89 \mathrm{a}$ & $2.015 \mathrm{~b}$ \\
\hline Coverage & $\mathrm{ns}$ & $* * *$ & $\mathrm{~ns}$ & $\mathrm{~ns}$ & $* * *$ \\
\hline
\end{tabular}

Note: CA, covered area, UA, uncovered area treatments. ns, not significant; significant at ${ }^{*} \mathrm{p}<0.05,{ }^{* *} \mathrm{p}<0.01,{ }^{* * *} \mathrm{p}<0.001$. Values belonging to the same characteristic with different letters within a column denote significant differences between the cover treatment according to the LSD test $(\mathrm{P}<0.05)$.

However, differences were found between treatments for the inflorescence dry weight where due to the higher photosynthesis rate in the covered cuttings, the inflorescence dry weight was $21.11 \mathrm{~g}$ while in the uncovered the average inflorescence dry weight was $16.87 \mathrm{~g}$.

Given the above figures, we evaluated the compactness index (Dry inflorescence weight/ inflorescence length, $\left.\mathrm{g} \mathrm{cm}^{-1}\right)$. The compactness index was higher in the covered pieces $\left(1.10 \mathrm{~g} \mathrm{~cm}^{-}\right.$ $\left.{ }^{1}\right)$ compared to the uncovered pieces $\left(0.88 \mathrm{~g} \mathrm{~cm}^{-}\right.$ $\left.{ }^{1}\right)$. In addition to performance, the compactness index is also a quality index.

The relative increase of CBD given by the reflection of radiation is $25 \%$. Similarly, the $\Delta$-THC content of leaves was $23 \%$ higher in UV irradiated plants than plants grown in non-irradiated conditions (Fairbairn and Liebmann, 1974).

\section{Conclusion}

In conclusion, the soil cover with a white agrotextile can offer two cultivation periods per year. On the covered area, the development was faster and the yield higher. Illumination at the base of the plantation, expressed as a percentage of the surface of photosynthetic active radiation (PAR), was higher in the covered area. For the SLA, the difference between the two treatments was about $15 \%$, because plants exploit to the maximum the Photosynthetically Active Radiation and produced thinner and larger surface leaves. Although, when the temperature exceeds $35^{\circ} \mathrm{C}$ the cover material must be removed because the relative growth rate is reduced. The number of inflorescences was not found to be affected by the cover material because it is mainly controlled by genetic factors rather 
than by cultivation practices. Finally, CBD content was higher on covered area.

Acknowledgment: This work was funded by THRACE Nonwovens \& Geosynthetics S.A. The code number of this project on the Special Account of the Agricultural University of Athens is 34.0444.

\section{References}

1. Ajmeri JR, Ajmeri CJ (2016). Developments in nonwovens as agrotextiles. In Advances in Technical Nonwovens Woodhead Publishing, 365-384.

2. Albert T, Karp K, Starast M and Paal T. (2010). The effect of mulching and pruning on the vegetative growth and yield of the half-high blueberry. Agronomy Research, 8: 759-769.

3. Amaducci S, Zatta A, Raffanini M, Venturi G (2008). Characterisation of hemp (Cannabis sativa L.) roots under different growing conditions. Plant and Soil, 313: 227.

4. Anade PD (2013). Applications of coir in agrotextiles. Asian Textile Journal, 22: 50-52.

5. Bhatt P, Rani A, Gahlot M, Bhandari V (2019). Recycling and Reuse of Agrotextiles Used in Agricultural Farms. International Journal of Current Microbiology and Applied Sciences, 8: 1566-1576.

6. Bhattacharyya R, Yi Z, Li Y, Li T, Panomtaranichagul M, Peukrai S, Chau Thu D, Cuong T, Thi Toan T, Jankauskas B, Jankauskiene G, Fullen M, Subedi M, Booth C (2012). Effects of biological geotextiles on aboveground biomass production in selected agro-ecosystems. Field Crops Research, 126: 23-36.

7. Bilalis D, Karkanis A, Angelopoulou F, Travlos I, Antoniadis A, Ntatsi G, Lazaridi E, Savvas D (2015). Effect of organic and mineral fertilization on root growth and mycorrhizal colonization of pea crops (Pisum sativum L.). Bulletin of University of Agricultural Sciences and Veterinary Medicine Cluj-Napoca. Horticulture, 72(2): 288-294.

8. Carpus E, Dorogan A, Burnichi F (2018). Agrotextile Systems - Strategic Elements for Sustainable Development of the Agriculture. ICAMS $2018-7^{\text {th }}$ International Conference on Advanced Materials and Systems, 307-311.

9. Chailakhyan MK, Khryanin VN (1978). The influence of growth regulators absorbed by the root on sex expression in hemp plants. Planta, 138: 181-184.

10. Criddle RS, Smith BN and Hansen LD (1997). A respiration based description of plant growth rate responses to temperature. Planta, 201(4): 441-445.

11. Deloitte (2016). Modelling the cost of medical cannabis. Deloitte Access Economics Pty Ltd, Australia.
12. Dierickx W (1999). Opening size determination of technical textiles used in agricultural applications. Geotextiles and Geomembranes, 17(4): 231-245.

13. Dijkstra P (1989). Cause and effect of differences in specific leaf area. Unknown Journal, 125-140.

14. Fairbairn JW and Liebmann TA (1974). The cannabinoid content of Cannabis sativa L. grown in England. J. Pharm. Pharmac. 26: 413-419.

15. Folina A, Roussis I, Kouneli V, Kakabouki I, Karidogianni S, Bilalis D (2019). Opportunities for cultivation of medical cannabis (Cannabis sativa L.) in Greece. Scientific Papers. Series A. Agronomy, 62(1): 293-300.

16. Gangopadhyay UK, Hira M (2010). Towards popularising agrotextiles in India. Man Made Textiles in India, 53: 41-46.

17. Jankauskienė Z and Gruzdevienè E (2010). Evaluation of Cannabis sativa cultivars in Lithuania. Žemdirbystė/ Zemdirbyste-Agriculture, 97(3): 87-96.

18. Kobza J and Edwards GE (1987). Influences of leaf temperature on photosynthetic carbon metabolism in wheat. Plant physiology, 83(1): 69-74.

19. Lydon J, Teramura AH and Coffman CB (1987). UV-B radiation effects on photosynthesis, growth and cannabinoid production of two Cannabis sativa chemotypes. Photochemistry and Photobiology, 46(2): 201-206.

20. Manna K, Kundu MC, Saha B, Ghosh GK (2018). Effect of nonwoven jute agrotextile mulch on soil health and productivity of broccoli (Brassica oleracea L.) in lateritic soil. Environmental monitoring and assessment, 190(2): 82 .

21. Marasović P, Dragana K (2019). Overview and perspective of nonwoven agrotextile. Textile and Leather Review, 2(1): 32-45.

22. Restrepo Osorio A, Álvarez-López C, Jaramillo N, Fernandez-Morales P (2019). Agrotextiles and Crop Protection Textiles. In: Roshan P. (ed.), High Performance Technical Textiles, John Wiley \& Sons, pp. 279-318.

23. Ryan MH, Graham JH (2002). Is there a role for arbuscular mycorrhizal fungi in production agriculture? Plant and Soil, 244: 263-271.

24. Scarlat R, Rusu L, Pricop F (2017). Knitted agrotextiles for a sustainable agriculture. Industria Textila, 68: 332336.

25. Sidiras N, Bilalis D, Vavoulidou E (2001). Effects of tillage and fertilization on some selected physical properties of soil $(0-30 \mathrm{~cm}$ depth) and on the root growth dynamic of winter barley (Hordeum vulgare cv. Niki). Journal of Agronomy and Crop Science, 187(3): 167-176. 
26. Struik PC, Amaducci S, Bullard MJ, Stutterheim NC Venturi G, Cromack HTH (2000). Agronomy of fibre hemp (Cannabis sativa L.) in Europe. Industrial crops and products, 11(2-3): 107-118.

27. Swapan K, Bairagi G, Bhattacharyya S, Murari R, Mondal M (2016). An Overview on Test Standards for Evaluation of Jute Agrotextiles. American Journal of Engineering Research, 5: 49-53.

28. Vamerali T, Saccomani M, Bona S, Mosca G, Guarise M, Ganis A (2003) A comparison of root characteristics in relation to nutrient and water stress in two maize hybrids. Plant Soil 255:157-167.
29. Van der Werf HMG, Haasken HJ, Wijlhuizen M (1994). The effect of daylength on yield and quality of fibre hemp (Cannabis sativa L.). European Journal of Agronomy, 3(2): 117-123.

30. Vera CL, Malhi SS, Raney JP, Wang ZH (2004). The effect of $\mathrm{N}$ and $\mathrm{P}$ fertilization on growth, seed yield and quality of industrial hemp in the Parkland region of Saskatchewan. Canadian journal of plant science, 84(4): 939-947.

31. Werf HVD, Brouwer K, Wijlhuizen M, Withagen JM (1995). The effect of temperature on leaf appearance and canopy establishment in fibre hemp (Cannabis sativa L.). Annals of applied biology, 126(3): 551-561. 